\title{
Technology Acceptance Model as a Mediator Explaining Factors Affecting Online Education
}

\section{Mayar Farrag Singab Elsayed}

Marketing and Innovation Department

Phd Business Administration

mfarrag@ecu.edu.eg

\section{Manal Elsayed Abdelhamid Shabbat}

International business Department

Phd Public Administration

melsayed@ecu.edu.eg

Faculty of Economics and International Trade

Egyptian Chinese University, Egypt

\begin{abstract}
Purpose - This study aims to provide educators with information concerning factors impacting the student's willingness to use online learning. This is explained by the mediator technology acceptance model (TAM). The study investigates the external factors and the mediating effect of the perceived ease of use, and perceived usefulness on the intention to use online learning.

Design/methodology/approach Results are obtained from surveying 202 university students, 80 of which are undergraduates, while 122 are postgraduates. Public and private universities are represented in the sample, as $53 \%$ of the sample are private university students, while $47 \%$ are public students. $62.4 \%$ are students outside Cairo, whereas $37.6 \%$ are from residential areas outside Cairo. Smart PLS 3 has been used to test the hypothesis, directly and indirectly involving testing mediation.

Findings - There is no direct relation between the instructor's online self-efficacy, student online self-efficacy, and the student willingness to use online education. Nevertheless, there is a significant direct relationship between organizational support and student intention to use online education.

Originality/value - This research adds to the knowledge accumulation of online learning studies, it discusses online learning in the context of Egypt's higher education during COVID 19 crises. As, the Egyptian case provides an enriched applied case of a developing country that could face the negative repurctions of COVID 19 on the students in the higher education system.

Data represent the educational form and level that might affect student behavioral intention to learn online. Having the TAM as the mediator affects the relations between variables. This study will provide educators responsible for the management and development of online learning with significant information about how students perceive online learning and ways to encourage adoption by students.
\end{abstract}

Keywords: Online Learning, Technology Acceptance model, Higher Education, COVID-19.

\section{Introduction}

Online learning has increasingly become an essential component in institutions of higher education. The literatures define online learning as an educational field that focuses on the dissemination of academic knowl-

* This article was submitted in November 2021, and accepted for publishing in January 2022.

(c) Arab Administrative Development Organization- League of Arab States, 2025, pp 27-246، DOI: 10.21608/aja.2022.104817.1177 
edge and information to different geographical locations (Chen,X. Sun, A. 2016). Users of online learning in higher education have different attitudes towards the use of the technology. The intentions to use, as well as the actual usage, of information systems are important requirements for online learning in different universities. Online learning is a significant element in the future of education, as it provides a comfortable, easy, fast, and affordable learning environment. Due to the pandemic, institutions of higher education were forced to shift to online learning. As a result, they developed emergency scenarios that help users migrate to remote learning, and design and implement teaching systems remotely.

Online learning has become a popular learning factor provided by most educational institutions around the world, via the Internet and Web portals. It has revealed that students and instructors, while physically distant, need a mediatory tool through technology, and the design of a learning context.

COVID-19 has been the greatest challenge to educational systems. It has created changes in the process of learning in higher education, and has affected the communication between instructors and students. While both institutions and students are forced to complete their predefined syllabi according to the academic calendar, a Learning Management System is needed, in the form of a software that encompasses various services to help students managing their courses. By this meaning tudents' online learning experience during the COVID-19 pandemic has identified several major concerns, challenges, services. (Yan, L. et al. 2021)

These services include monitoring and evaluating students, and providing grades, as well as the additional administrative actions required for educational processes in higher education. With the pandemic spreading, many countries have shut down all the educational institutions, shifting to online learning platforms to keep the academic processes going. Many scholars have discussed the university members' perceptions of online learning experiences based on age, gender, level of education, in addition to teaching experience, technical competence, and awareness of the benefits of online learning.

The purpose of this study is to investigate university students' adoption, usage, and acceptance of online learning. Moreover, the study aims to provide a developed model by examining the relation between the external factors: the individual efficacy, the instructor efficacy, and the organizational support. This is achieved using the two main components of the Technology Acceptance Model, which are the perceived ease of use, and the perceived usefulness. They are investigated as mediators applied in the Egyptian system of higher education, whether private or public, according to the perspective of the graduate and undergraduate students, and according to the nature of the different fields of study, in the different faculties and institutes.

\section{Material Studied}

This research paper is developed in three sections. Section I, covers the historical background, and the conceptual framework. Section II, discusses online learning in the Egyptian system of higher education, Section III, presents the research design, and the result discussion. The paper concludes with the findings, implications, and recommendations for future research.

\section{Section I: Theoretical Background and Conceptual Framework}

This section discusses online learning from the viewpoint of Technology Acceptance Model. The theoretical framework, historical background, and conceptual framework are explained as follows:

\section{Theoretical Background}

The Technology Acceptance Model (TAM) is originally an extension of the Theory Reasoned Action (TRA). Davis had first introduced TAM in his Ph.D. Thesis in 1986. Three years later, Davies (1989) created 
TAM to explain why users accept or reject information technology, by adopting TRA. TAM has been employed in various research studies. Therefore, it has become significant to technology acceptance, since the attitude itself affects the behavioral intention to use a particular technology, and predicts the actual system use (Vululleh, 2018).

Consequently, PEOU has a direct influence on PU. According to Davis et al. (1989), PEOU refers to the level to which users feel they can minimize their efforts using a specific technology. PU, also, refers to the level to which users feel they can improve and increase their job performance using a specific technology. Salloum, A. et. al (2019) confirmed the same conclusion, highlighting that PEOU is related to system design and features, whereas PU minds with effort decreasing.

Al- Adwan, A. et al. (2013) argued that the relationship between the two components indicates that PU and PEOU jointly predict the attitudes towards using technology. In addition, PU influences the user's behavioral intention in using technology, while intention to use determines the actual use of technology. Furthermore, the model supposed that PEOU is likely to influence PU, where the increase of PEOU leads to performance improvement.

As stated by Ngampornchai A. (2016), TAM has shown a great importance in explaining and predicting information technology user behavior. This research suggests that TAM is the most suitable model to explore the acceptance of online learning. According to TRA, behavior is driven by behavioral intention, which is one of the functions of individual attitudes, and subjective norms of the behavior in question. TRA suggests that intention is the main determinant of an individual's behavior, whereas intention to behave is determined by subjective norms.

TAM, as seen by Almarabeh, T. (2014), has proven to be helpful in analyzing the way students intend to use online learning. The model has been developed by Fred Davis, who believed that the individual's acceptance of the technology integration is an important factor for the success of the information systems. The model explains the relations behind the features of a system, the way people behave while using it, and the attitude people may have towards using the system, which is influenced by PU and PEOU.

A unified theory of acceptance and use of technology (UTAUT) has been developed by Venkatesh, Morris, Davis, and Davis (2003) because the constructs of TAM have been recognized as unable to fully explain the students' acceptance of the online learning environment in higher education. UTAUT consists of essential determinates from eight models of technology acceptance. When tested empirically, UTAUT was found to explain $70 \%$ of intentions to use, and actual use of information systems. The four core determinants of UTAUT are performance expectancy, effort expectancy, social influence, and facilitating conditions.

Nassuora (2013) concluded that the UTAUT model has become one of the most widely used in the field of information and communication technology acceptance model, which could explain $70 \%$ of technology acceptance behavior.

To conclude, it is agreed upon that TAM is an appropriate model for predicting the acceptance of several technologies with two main components, namely PU and PEOU, as key elements influencing users' attitude, intention, and actual behavior to use a new technology. Finally, users are more interested in using a new technology, when they think it helps them do their jobs. Successful online learning engagement requires that users have a positive attitude towards it. Therefore, attitude to use has been supposed as a direct determinant of intention to use.

\section{Conceptual Framework}

Garrison (1990) explained that the origins of online learning as a concept dates back to 1728, when a shorthand teacher looked for students to take weekly lessons, as shown in an advertisement in the Boston 
Gazette. The postal service was the tool used to carry out the initiative. London University is believed to be the first university to provide distance learning courses.

In accordance with Garrison, Coman, C. et al. (2020) mentioned that early types of distance education date back to 1840, when Isaac Pitman used mail and a shorten technique to teach and collaborate with students. However, the term e-learning began to be used in the educational process in the mid-1990s. As a result, it can be viewed as a natural evolution of the distance learning concept. Accordingly, Alenezi (2012) e-learning (EL), distance learning $(\mathrm{DL})$, and online learning $(\mathrm{OL})$ refer to the same concept, and depend on using technology to provide educational services using electronic means, such as audio, video, networking, and computer technologies to deliver and participate in learning process.

According to Salloum, A. et al (2019), OL is defined as a method of adopting new ways to enhance learning, and identifying the implemented educational model based on the electronic tools used in achieving interaction. Likewise, Tzivinikou, A. et al. (2020) outlined that online learning is a learning method that is different from traditional methods. It was the only educational solution during COVID-19 pandemic.

Alex A. Nwankwo (2015) confirmed that OL systems allow many people to access the internet, and hence education, by means of the provided online learning, through the different technological devices, and virtual environments. As a result, $\mathrm{OL}$ is considered an educational format by which students access content, participate in virtual discussions with an instructor and other students, submit assignments, and receive feedback electronically over the Internet (Laaser, 2011).

Similarly, Coman, C. et al. (2020) highlighted a more inclusive definition of OL as a particular teaching and learning type that integrates electronic resources and media, in order to accelerate development, and make education more qualitative. Moreover, it can be viewed as a system used for formal teaching, or a network through which information is provided via electronic tools to a large number of students.

In other words, online learners experience a higher level of independence and responsibility in completing the learning process because they understand the behaviors that help them learn, and apply these strategies proactively. In addition, online learning is flexible since students can determine when and where they learn. They can self-control their time and content (Mahyoob, M. 2020).

In short, OL mainly refers to using various electronic mediums and platforms in transferring knowledge to fulfill students' needs. It has very specific features that support the learning-teaching process, such as technological tools and designs, e-learning platforms, content, and users/participants.

Hung et al. (2010) provided the conceptual framework used for measuring OL readiness in four dimensions: self-directed learning (SDL), learner control (LC), online communication self-efficacy (OCE), and motivation for learning (ML). Each element in this conceptual framework is developed based on research. SDL is a learning form that develops and controls one's own learning process. It offers students the opportunity to interact with instructors to enhance their learning objectives. Motivation for learning plays an important role in OL because it is necessary to ensure that students remember, understand, and apply knowledge. Moreover, OCE element affects the use of technology for learning.

According to Chung et al. (2020), students who have high OCE experience little technological tension, as OCE results in online learning confidence. While OCE refers to the students' ability to adapt to online learning through transferring knowledge, LC refers to the level of which students can define their own learning processes. Thus, students can make their own decisions about the teaching review, and maximize their interests.

In short, the elements of the four dimensions are significant in studying the degree of learners' readiness. 
Nevertheless, online learning poses different difficulties. In his study, Mahyoob, M. (2020) highlighted that students face various challenges, such as the access to a personal computer, Internet connection, and online materials. Moreover, many students do not know how to use certain online tools because they differ from traditional ones, particularly with the lack of training on the usage of new learning tools.

To carry out online courses, adequate support should also be provided. Annan, D.L. (2008) concluded that having a good support team to tackle the hardware and software issues of the Internet system is required. Connectivity and unreliable electrical supply are considered challenges for both institutions, as well as the students involved in the online learning process.

\section{1- Technology Acceptance Model (TAM)}

A. Patricia (2020) explained that TAM implies the user's willingness, and the continuous technology usage. Researchers use TAM to understand the use and acceptance of OL. However, due to its limitations, the first model has been redefined multiple times. The model outlines $P U$ and $P E O U$ to be predictors of the behavioral intention to use an information system. (Keller, C. et al 2007).

In his study, Maajoon. A. (2012) agreed that PU of OL is the type of perception that results from using a particular technology when performing a particular job, which in turn determines the person's attitude. As mentioned by Keller, C. (2005), various studies used TAM in its original or extended versions, whereas others add value and comfort level when using computers in education. A third part uses models derived from literature on acceptance of computers, and using hypermedia. Furthermore, other studies use the Computer Attitude Scale regarding computer anxiety, computer confidence, computer liking, and computer usefulness. They concluded that students' anxiety or confidence regarding computer usage seems to influence the level of acceptance.

Farahat, T (2012) identified the factors affecting the students' acceptance of online learning, and determined how these factors based on TAM, can direct the students' intention to use online learning. He concluded that the students' perception of the ease of use, usefulness, attitudes towards online learning, and the students social influence are identified as important determinants of students' intention to practice online learning. The most noticeable finding is the possibility of utilizing the students' perceived ease of use, perceived usefulness, and attitudes towards online learning in predicting their behavioral intention to use online learning.

Different TAM sare analyzed by Kemp et al. (2019) who developed the factors affecting attitudes towards using educational technologies in institutions of higher education. They provide a category which included seven primary determinates which are: a) attitude, affect, and motivation; b) social factors; c) usefulness and visibility; d) instructional attributes; e) perceived behavioral control, f) cognitive engagement, and g) system attributes. All these factors are influential in adopting technology. They are introduced as follows:

\section{A- Attitudes, Affect and Motivation}

Regarding this category, A. Patricia (2020) confirmed that attitudes towards a behavior refer to the individual's positive or negative evaluation of the behavior. Students' attitudes towards online learning directly affect their learning process. Whereas affect refers to the individual's emotional state, motivation includes the satisfaction represented in the activity, the intention to achieve a goal, and the perceived relevance of an activity which affects behavioral intention.

\section{B- Perceived Behavioral Control}

Perceived Behavioral Control, as studied by D A Gayan (2021), refer to the degree to which a person can control any given behavior. People intend to adopt certain behaviors when they feel they are going to be successful in doing them. Increased perceived behavioral control is a mix of two dimensions: self-efficacy 
and controllability. Self-efficacy refers to the difficulty level required to perform the behavior, or to one's belief in his/her own ability to succeed in performing the behavior. Conversely, controllability refers to one's belief that he/she personally has control over the behavior performance, even when it is controlled by external factors.

\section{C- Cognitive Engagement}

As shown by C Richardson J., J Newby T. (2006), it involves the mental processes involved in classwork. It typically describes the ways students think deeply about ideas and concepts, how they make the presented material meaningful, and how they master the academic content. Similarly, A. Patricia (2020) described it as the cognitive processes that allow the user to absorb the knowledge, and feel a state of deep involvement. It includes focusing attention, engaging curiosity, concentration, and flow.

Hence, when users enjoy having high perceived behavioral control, they experience increased confidence in the ability to perform successfully. Online learning material must be provided in a way that ensures the enhancement of the learning experience, by focusing on the goal of knowledge absorption.

\section{Section II: Online Learning in Egyptian Systems of Higher Education}

This section discusses the educational format shift from traditional teaching to full-scale online education in the Egyptian institutions of higher education. It is organized into two parts as follows:

\section{Online Learning Experience in Systems of Higher Education}

Educational institutions highly prefer online platforms for knowledge sharing, and learning purposes. As discussed by Alhumaid, K. et al. (2020), educational institutions pay specific attention to online systems, in order to facilitate knowledge dissemination.

Mittal, A. et al (2021) explained that the only way for institutions to cope with COVID-19 was to move to virtual classrooms, and develop online learning. However, despite the vast online learning technologies, their usage was inefficient. The lack of senior management, responsible for evaluating the effectiveness of using such technologies resulted in minimum technology usage.

COVID-19 has forced universities to adopt online learning. This was explained by Thongsri, N. et al. (2019), confirming that this type of learning could facilitate communication between students and instructors. Furthermore, applying advanced technology has a great impact on introducing new learning opportunities, especially in developing countries.

Muthuprasad T. et al (2020) added that many countries decided to shut down educational institutions with the spread of COVID-19. By mid-March 2020, nearly 75 countries announced the closure of educational institutions. By the end of April 2020, 186 countries implemented nationwide closures, affecting about $73.8 \%$ of the total number of enrolled students. These decisions affected $91.3 \%$ of the student population worldwide. Educational institutions investigated some vital factors, such as the universities' readiness for closure, the intention to deal with different challenges before providing online courses, the support provided to disabilities, blending appropriate approaches, limiting the quantity of used platforms, developing online learning rules, and controlling students' learning performance (Drane, C., et al. 2020).

Aligned with Fischer, H. (2014) who viewed that the system of higher education is in a continuous process of change, information technologies and online learning systems are seen as key factors in achieving the universities' strategic goals. A study found that the quality of online learning, administration process, quality of instruction, as well as the quality of administrative and support services have a direct impact on 
the students' loyalty, manifested in the students' friendliness with online learning websites (Nafrees, A. et al., 2020).

Habes et al. (2019), and Angela, Sylvia, C., et al (2018) confirmed that improved communication technologies facilitate learning systems, mostly through the accessibility of useful information sources, and communication. Users consider online technology as a positive element of their learning system. Therefore, adapting to online learning has increased, due to the ease of access, and positive outcomes.

Arkorful, V. (2014) noted the benefits of online learning in higher education, such as flexibility and ease of access to a huge amount of information, the student's motivation to interact with each other, the exchange and respect of different points of view, as well as focusing on the needs of individual learners rather than those of the instructor, or the educational institution.

Many universities providing online learning services faced challenges in adopting successful strategies, including the acceptance and effectiveness of delivering courses. Understanding the students' acceptance of online learning is considered the most important issue when implementing and developing a successful online learning context (Al- Adwan, A. et al. 2013).

Butnaru, G. (2021) argued that university management should understand how students perceive and participate in online learning, and determine the factors influencing students' beliefs about it, in order to create new mechanisms to encourage students to engage in online learning systems. Sun, L., et al. (2020) confirmed that the COVID-19 crisis had a great impact on traditional educational progress, adding that universities may profit from this unprecedented opportunity, discover deficiencies, and accelerate the reform of online education through efficient management. The impact of the pandemic on education, universities, and users has triggered the investigation of students' perception about online learning during the pandemic. Allo M. (2020) concluded that students have a positive attitude towards online learning, as they consider it helpful and useful in the time of the crisis.

On the contrary, mok, k. et al. (2021) argued that COVID-19 is likely to have negative effects on the learning outcomes, graduation rates, employability, and job students' prospects, and on the economic health of the institutions of higher education.

Tan, C. (2021) suggested that online learning is vital in enhancing students' involvement, and analytical skills. However, faculty members face obstacles when creating the community of inquiry, and when delivering their course within an online learning context. These obstacles include the preparedness of educators, lack of experience in preparing online learning content, the poor instructor-student interaction in online learning practice, and the unreliable assessment of the online educational environment, etc. Other studies, also, support that online learning exhibits certain disadvantages.

Arkorful, V. (2014) argued that making the learning material available online results in improved learning outcomes, only for certain types of collective assessment. He argued that the most common disadvantage of online learning is the complete absence of vital personal interactions, not only between learners and instructors, but also among the community of learners. Hence, with these current challenges, universities must promote online teaching methods, and improve the infrastructure to mitigate problems.

\section{Online Learning in the Egyptian Systems of Higher Education.}

\section{1- The Background of Online Learning in Egypt.}

Wahab A. (2008) confirmed that there are two significant government initiatives of OL provided in Egypt, namely the internet, and the personal computer initiatives. The Ministry of Communications and Information Technology maintained free internet access nationwide, since 2002, through which more than 
15,000 ports serve 2 million internet users who pay only for the local dialup phone tariffs. In addition, affordable PCs and laptops were made available to students and professionals, according to a monthly installment plan that could be financed by a low interest loan. The Supreme Council of Universities signed a number of agreements with international institutions of higher education, in order to exchange knowledge and experience on the use of advanced technologies, including OL. Hussein, A. et al (2009) mentioned some e-learning initiatives, such as the Arab Open University, the Mediterranean Virtual University, Avicenna Virtual Campus, the Egyptian E-Learning University, as well as the National E-Learning Centre. They could provide online learning, infrastructure information, training, and support, in addition to nationwide coordination for e-learning development for both staff and students.

El-Seoud S. et al (2014) added that the Ministry of Higher Education programs were as follows: 18 e-learning labs, 6 personal computers (PCs) and servers, in addition to the Local Area Network (LAN) installed in all of the 17 public universities. Moreover, 20 e-learning labs for students, 20 PCs, and LAN accessibility were installed in universities. In 2008, 81.4\% of Egyptian institutions of higher education had computer labs and Internet access, while $98.7 \%$ of the students had personal computers (PCs). The Faculty of Engineering at Ain-Shams University and at Assiut have been equipped with the latest technologies of e-learning, offered by the HP Company. Furthermore, in their study, El-Seoud S. et al (2014) explained that the British University in Egypt -which is a private validated university- and Helwan - a governmental university- have introduced OL, as an educational tool to support traditional face-to-face lectures/classes.

According to Mekky, S. (2021), in 2020, Egypt witnessed a fast-growing interest and need, as a result of the COVID-19 pandemic.

To conclude, the educational system in Egypt valued the importance of OL as a vital tool in today's education after the pandemic.

\section{2- The Recent Efforts in Egypt's Online Learning}

The repercussions of the COVID-19 pandemic reached most countries of the world, including Egypt. The first consequence was the closure of educational institutions. The Egyptian Ministry of Higher Education adopted a plan to ensure the continuation of the educational process. As discussed by Shahin, Y. (2021), the Ministry of Communications and Information Technology launched a number of initiatives to support OL, in coordination with the National Telecommunications Regulatory Authority, and the companies providing telecommunications services in Egypt. 20\% of the monthly download capacities were added to home Internet subscriptions free of charge for individuals, at a cost of 200 million pounds to facilitate student access to educational platforms.

According to the Central Agency for Public Mobilization and Statistics (2020), the total number of students in Egypt's higher education exceeds 3 million in 27 governorates. As a result, Egyptian universities had considered the necessity of integrating online teaching tools into the educational process, in light of the global pandemic. Since March 2020, the Supreme Council of Universities declared and approved the implementation of migration to online learning, starting with e-content and towards full-scale online courses, according to the technological infrastructure and human capital capacities. In addition, the Egyptian Prime Minister amended executive regulations of the universities law to accredit online examination assessment (Decision \#1200 Year 2020, where Article 79 stipulates). Internal regulations integrated online teaching systems into the nature of the field of study, in the different faculties and institutes. Such dramatic transformation in the system of higher education in Egypt required the evaluation of key users' satisfaction with the newly adopted educational system.

Online learning in higher education in Egypt faced some challenges, as mentioned by Hammad, A. et al (2020). The Egyptian authorities announced the suspension of all academic activities, including university 
lectures, to limit infection. Consequently, the teaching staff and the students in Egyptian universities had been directed to online learning. The teaching staff depended on recorded online lectures. However, during the first weeks of the COVID-19 crisis, the Egyptian public universities recorded some shortcomings. As a result, students were not confident in the amount of knowledge they receive from this electronic mode of teaching.

\section{Section III: Research Design and Results Discussions.}

This section will be provided through three parts, descussions, findings and future agenda

\section{Disscussions}

Sudden transformation to fully online teaching techniques and tools is doubtful! That is why there is a necessity to investigate a the key external factors affecting the intension to use online learning, it is also very important to know which factor has more influence on intension and to understand the mediating effect of the technology acceptance model .

Questions were selected to explore and assess both positive and negative students responses regarding the external factors and their impact on perceived ease of use and perceived usefulness and hence its impact on online learning intension to use. The items and constructs were an adaptation of others" work in the literature (Park 2009; Hammoud 2010; Worrall 2011).

To measure students' responses to the above dimensions, a 5-point Likert scale was used. Data for the present study were collected in 2020 and the questionnaire consisted of four large blocks. The first four blocks included questions related to external factors (self-efficacy, instructor efficacy and organizational support), the second part was the mediating effect of perceived ease of use (PEOU) and perceived usefulness (PU) and finally, intension to use. These four parts were anchored by "Strongly agree" (5) and "Strongly disagree" (1). Finally, the fourth and last block included questions about demographic like, university type, education level, gender, internet speed, no.of courses and platform used.

\section{Hypotheses}

Researches like (Arbaugh 2000) noted the positive relationship between learners progress when satisfied with online system . further studies tackeled their motivation and ability (Piccoli, Ahmad et al. 2001).

Many studies researched the role of the instructor in influencing the students perception and acceptance of the online learning. (Al-Busaidi and Al-Shihi 2010; Lee, Hsiao et al. 2014).

According to (Sun, Ray et al. 2008) it was mentioned that how flexible and easy the technology affects how learners adopt the e-learning .

It was further discussed by many researches (Masrom, Rahiman et al. 2008; Parsazadeh, Megat et al. 2013) and (Al-Busaidi and Al-Shihi 2010) that providing organizational (university )support whether through technical support or teching systems helps to a great extent the adoption of both traditional and e-learning education.

\section{Mentioning the Above Discussion we Need to Formulate the Following Hypotheses:}

- H1: Students self-efficacy positively impact online learning acceptance

- $\quad$ H2: Students self-efficacy has a positive impact on Perceived usefulness (PU)

- H3: Students self-efficacy has a positive impact on Perceived ease of use (PEOU) 
- H4: Instructor efficacy positively impact online learning acceptance

- H5: Instructor efficacy has a positive impact on Perceived usefulness (PU)

- H6: Instructor efficacy has a positive impact on Perceived ease of use (PEOU)

- H7: Organizational support positively impact online learning acceptance

- H8: Organizational support has a positive impact on Perceived usefulness (PU)

- H9: Organizational support has a positive impact on Perceived ease of use (PEOU)

- H10: Perceived usefulness (PU) has a positive impact on students acceptance of online learning

- H11: Perceived ease of use (PEOU) has a positive impact on student's acceptance of online learning.

\section{1- The Measurement Model}

This study used partial least squares based-structural equation modelling method (PLS-SEM) to analyze data output from survey to overcome the problems attached to small sample size and those related to normality. To assess the model, some indicators were used; the variance inflation factor (VIF) used to evaluate collinearity of the formative indicators, Cronbach alpha, composite reliability (CR), AVE for each construct, rho, Fornell-Larchker criterion for assessing discriminant validity ( Hair et al., 2019).

Table 1

\begin{tabular}{|c|c|c|c|c|c|c|c|}
\hline & $\begin{array}{l}\text { Ease } \\
\text { of use }\end{array}$ & $\begin{array}{c}\text { Student online } \\
\text { efficacy }\end{array}$ & $\begin{array}{c}\text { Instructor } \\
\text { online efficacy }\end{array}$ & $\begin{array}{l}\text { Intention } \\
\text { to use }\end{array}$ & $\begin{array}{c}\text { Organizational } \\
\text { support }\end{array}$ & $\begin{array}{l}\text { Perceived } \\
\text { usefulness }\end{array}$ & $\begin{array}{c}\text { VIF should be } \\
\text { less than } 3\end{array}$ \\
\hline EOU1 & 0.819 & & & & & & 1.654 \\
\hline EOU3 & 0.793 & & & & & & 1.534 \\
\hline EOU4 & 0.855 & & & & & & 1.501 \\
\hline ind 2 & & 0.940 & & & & & 2.659 \\
\hline ind3 & & 0.951 & & & & & 2.659 \\
\hline instrselfeff1 & & & 0.870 & & & & 2.461 \\
\hline instructor5 & & & 0.829 & & & & 1.980 \\
\hline instructorself4 & & & 0.878 & & & & 2.430 \\
\hline instruselfefficacy3 & & & 0.824 & & & & 2.269 \\
\hline int1 & & & & 0.947 & & & 2.671 \\
\hline int3 & & & & 0.945 & & & 2.671 \\
\hline orgsupp1 & & & & & 0.871 & & 2.794 \\
\hline orgsuppo 2 & & & & & 0.862 & & 2.733 \\
\hline orgsuppo3 & & & & & 0.796 & & 1.309 \\
\hline usefulness2 & & & & & & 0.940 & 2.235 \\
\hline usefulness3 & & & & & & 0.927 & 2.235 \\
\hline AVE $>0.5$ & 0.676 & 0.895 & 0.723 & 0.895 & 0.712 & 0.871 & \\
\hline $\mathrm{CR}>0.8$ & 0.862 & 0.944 & 0.913 & 0.945 & 0.881 & 0.931 & \\
\hline Cronbach alpha $>0.7$ & 0.764 & 0.883 & 0.872 & 0.883 & 0.799 & 0.853 & \\
\hline Rho $<1$ & 0.788 & 0.889 & 0.878 & 0.883 & 0.802 & 0.857 & \\
\hline
\end{tabular}

All loadings are above 0.7

The internal reliability and validity of the measurement model shown in table 1 displays satisfactory measures as shown in the above table. Values of Cronbach alpha are all above 0.7 . The values of composite reliability (CR) are all more than 0.8 above the threshold recommended and rho_ $A<1$ for all latent variables. The discriminant and convergent validity are satisfied by more than one evidence. AVE values are all greater than 0.5, with the square roots of the AVE for each construct (establishing the convergent validity) and the diagonal figures shown in table 2 are greater than their highest correlation value with any other 
construct, satisfying Fornell-Larchker criterion for assessing discriminant validity. No cross loadings and dimensions are well loaded on their constructs with 0.7 as minimum loading ensuring the convergent and discriminant validity of the model.

Table 2: Diagonal Figures Satisfying Fornell-Larchker Criterion

\begin{tabular}{cccccc}
\hline & $\begin{array}{c}\text { Student online } \\
\text { self-efficacy }\end{array}$ & $\begin{array}{c}\text { ease of instructor online } \\
\text { use }\end{array}$ & $\begin{array}{c}\text { intension organizational } \\
\text { self-efficacy } \\
\text { to use }\end{array}$ & $\begin{array}{c}\text { perceived } \\
\text { support } \\
\text { usefulness }\end{array}$ \\
\hline Student online self-efficacy & 0.946 & & & & \\
\hline ease of use & 0.699 & 0.823 & & & \\
\hline instructor online self-efficacy & 0.664 & 0.743 & 0.850 & & \\
\hline intension to use & 0.639 & 0.860 & 0.761 & 0.946 & 0.844 \\
\hline organizational support & 0.617 & 0.712 & 0.815 & 0.795 & 0.775 \\
\hline perceived usefulness & 0.650 & 0.828 & 0.745 & 0.855 & 0.934 \\
\hline
\end{tabular}

\section{2- The Structural Model}

Bootstrap method with 1000 subsamples was used to test previously stated hypotheses. PLS-SEM model fit indices are measured by SRMR, NFI, $\mathrm{dG}$ and dULS. Tested model indicates acceptable model of fit indices (Henseler et al., 2016) with SRMR $=0.08 \leq 0.08, \mathrm{NFI}=0.685, \mathrm{dG}=0.89<0.95$, dULS=0.87 $<0.95$.

Figures 1 and 2 show that $64.1 \%$ of the variance in ease of use is explained by three factors; student online self-efficacy with $\mathrm{B}=0.335$, instructor online self-efficacy with $\mathrm{B}=0.324$ and organizational support. with $B=0.242, p<0.001$. Also, $65.9 \%$ of the variance in perceived usefulness is explained by three factors: student online self-efficacy with $B=0.217$, instructor online self-efficacy with $B=0.234$, and organizational support with $B=0.449$. Moreover, Figure 1 and 2 show that $82.6 \%$ of the variance in student intention to use online education is explained mostly by ease of use with $B=0.433$, perceived usefulness with $B=0.302$, and organizational support with $\mathrm{B}=0.240$, all significant at $\mathrm{P}<0.001$. 


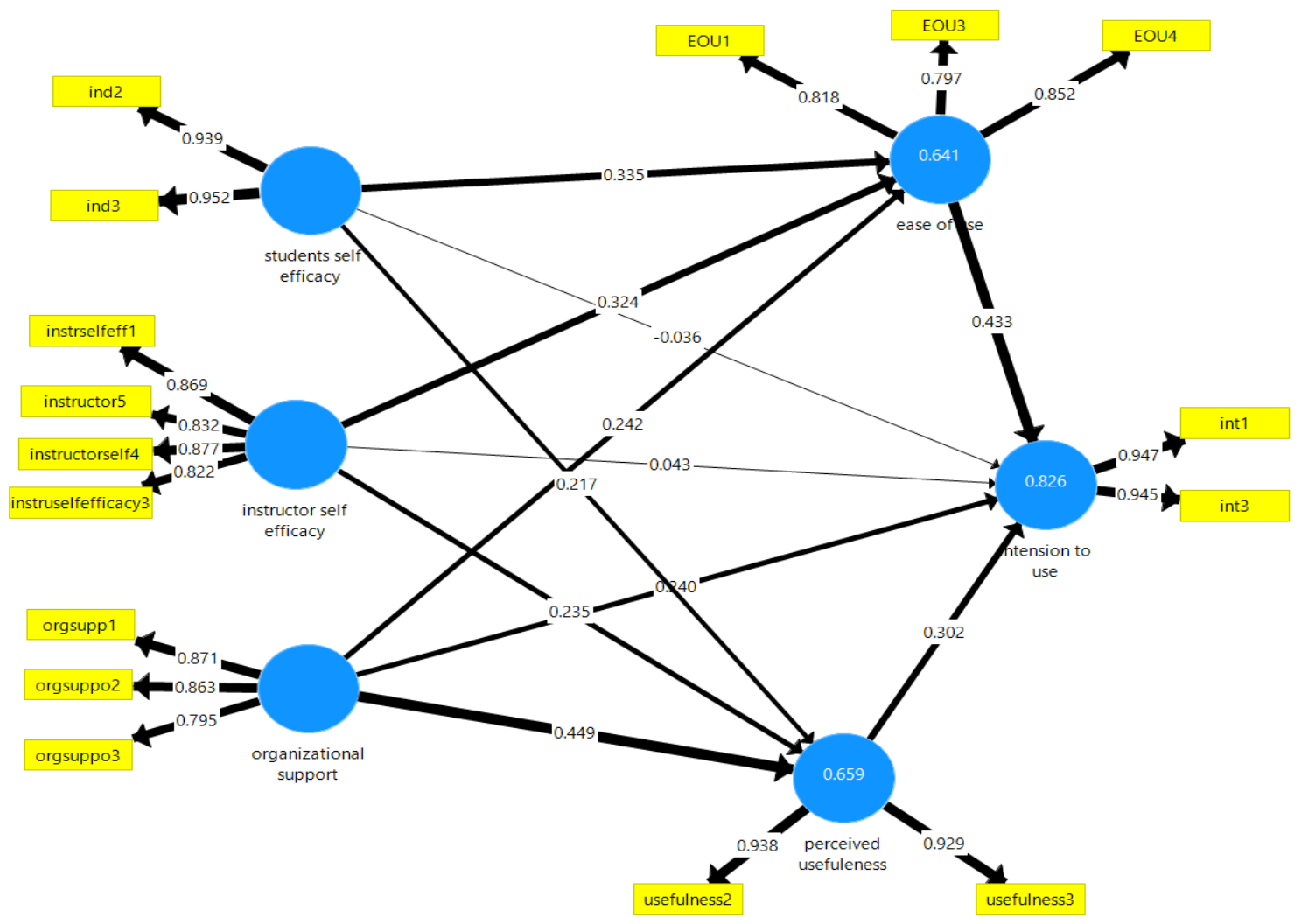

Figure 1: Adjusted R Square Calculations

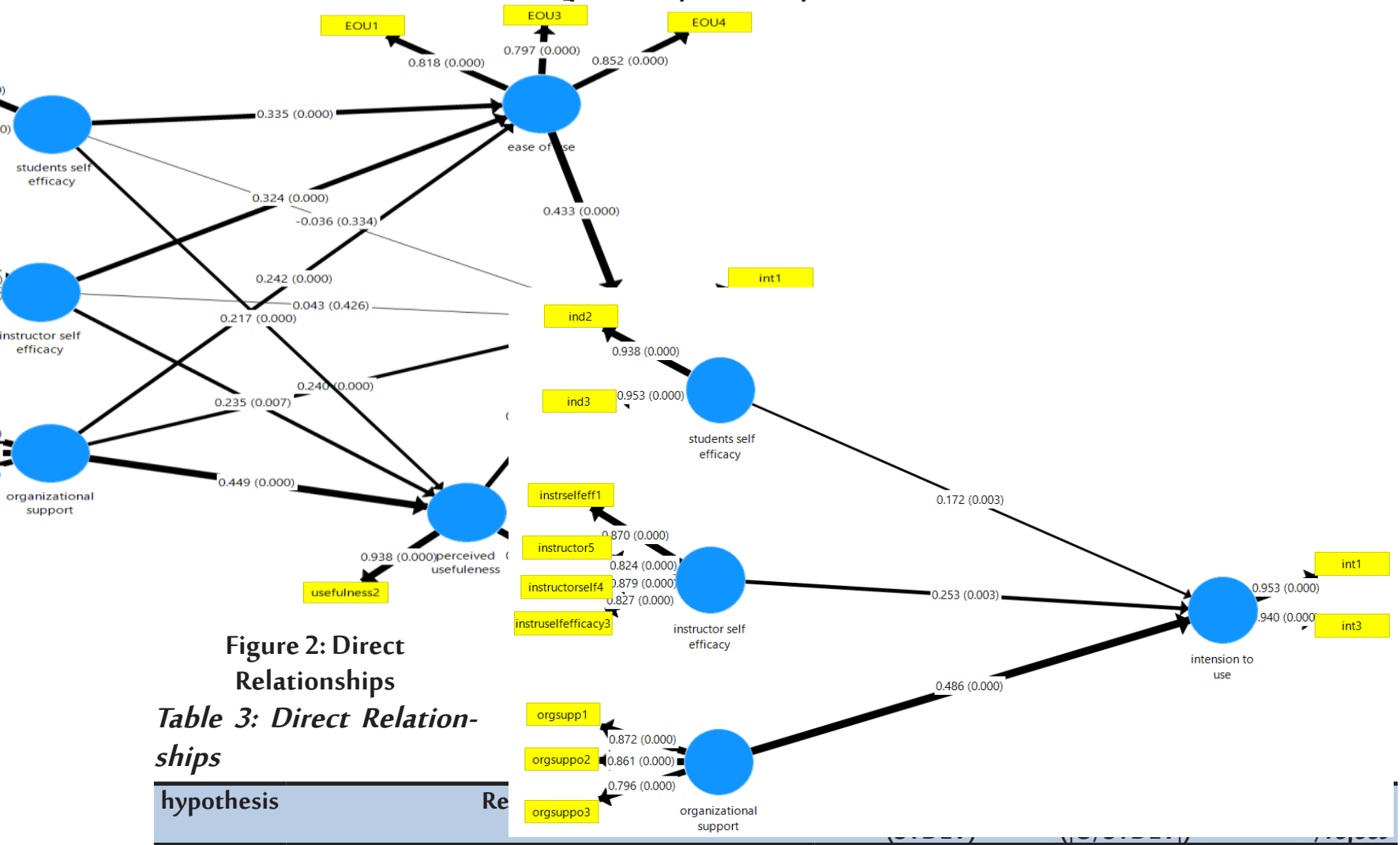

H3 Student online self-efficacy -> ease of use

Figure 3: With Who Mediation $^{4.938}$ 


\begin{tabular}{cccccc}
\hline hypothesis & Relationship & $\begin{array}{c}\text { Standard Deviation } \\
\text { (STDEV) }\end{array}$ & $\begin{array}{c}\text { T Statistics } \\
\text { (O/STDEV|) }\end{array}$ & $\begin{array}{r}\text { P Values } \\
\text { Accept } \\
\text { /reject }\end{array}$ \\
\hline $\mathrm{H} 1$ & Student online self-efficacy -> intension to use & 0.038 & 0.967 & 0.334 & Reject \\
\hline $\mathrm{H} 2$ & Student online self-efficacy -> perceived usefulness & 0.060 & 3.601 & 0.000 & Accept \\
\hline $\mathrm{H} 11$ & ease of use -> intension to use & 0.059 & 7.387 & 0.000 & Accept \\
\hline $\mathrm{H} 6$ & instructor self-efficacy -> ease of use & 0.077 & 4.186 & 0.000 & Accept \\
\hline $\mathrm{H} 4$ & instructor self-efficacy -> intension to use & 0.054 & 0.796 & 0.426 & Reject \\
\hline $\mathrm{H} 5$ & instructor self-efficacy -> perceived usefulness & 0.087 & 2.693 & 0.007 & Accept \\
\hline $\mathrm{H} 9$ & organizational support -> ease of use & 0.068 & 3.536 & 0.000 & Accept \\
\hline $\mathrm{H} 7$ & organizational support -> intension to use & 0.063 & 3.801 & 0.000 & Accept \\
\hline $\mathrm{H} 8$ & organizational support -> perceived usefulness & 0.071 & 6.316 & 0.000 & Accept \\
\hline
\end{tabular}

\section{3- Mediation Analysis}

The mediators tested in the model are ease of use and perceived usefulness. Table 3 shows no direct effect between the tested independents instructor online self-efficacy and student online self-efficacy and the dependent represented in the student intention to use online education. While it shows direct significant relationship between the independent variable organizational support and student intention to use online education.

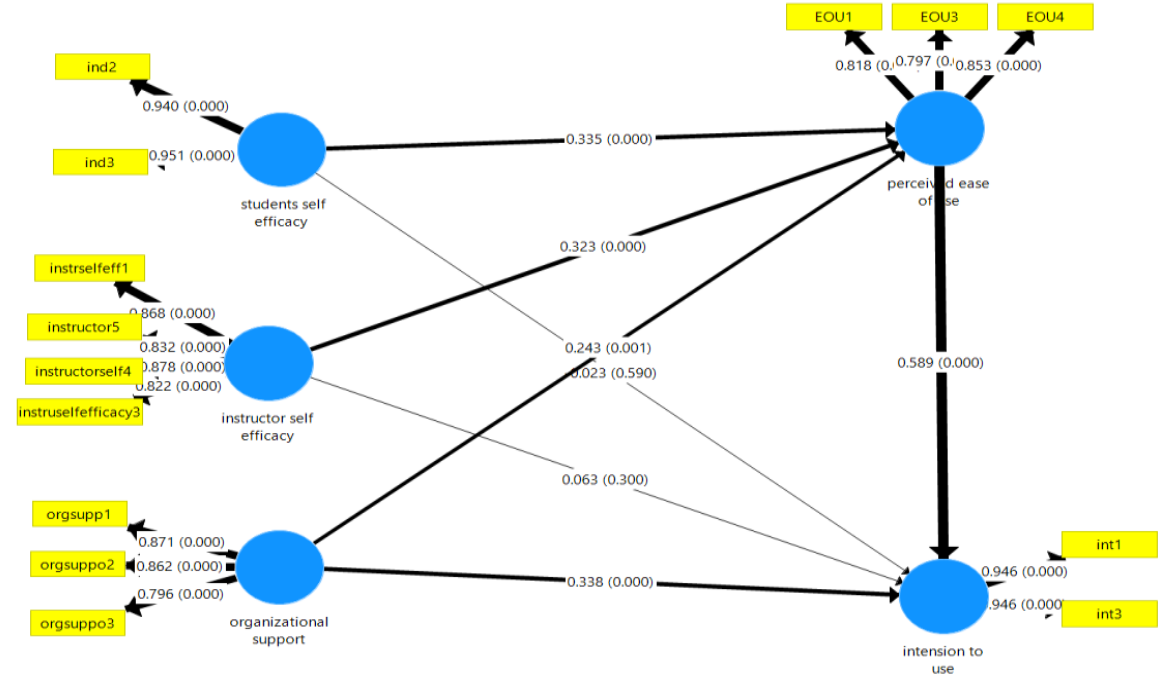

Figure 4: When Ease of Use is a Mediator

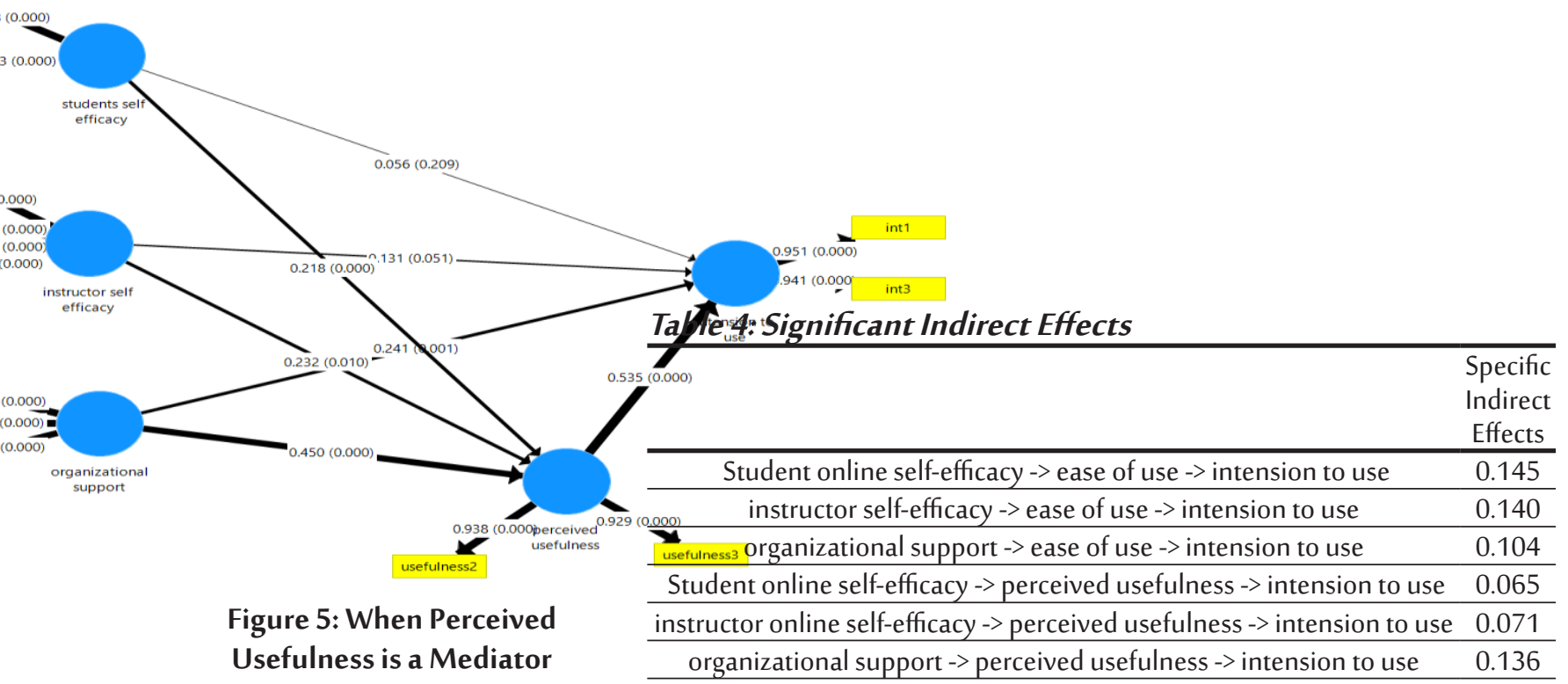


Tables 3 and 4 ensures full mediation of ease of use and perceived usefulness in the relationship between the two independent variables student online self-efficacy and instructor online self-efficacy and the student intention towards online education. The indirect relations show positive signs indicating a positive effect of mediators on the relationship between the mentioned independents and dependent tested.

For testing the role of mediation of the ease of use and perceived usefulness between organizational support and intention to use online education, it is clear from table 3, figure 3, table 4, there is partial mediation according to Nitzl, C., Roldan, J. L., \& Cepeda, G. (2016). To sum up mediation of ease of use and perceived usefulness in the model tested is accepted.

\section{Findings}

As revealed from the findings, it was shown that student's efficacy has no impact on the intension to use online learning. Having the skills and abilities doesn't necessarily make them wanting to use the online learning. Something was needed to influence this effect which was the mediating role of the perceived ease of use and the perceived usefulness. This was proved to significantly affect their intension.

Regarding the mediating effect of PEOU, the easiness of the platform, knowing how to find needed information, the presence of clear instructions, the ability to load and upload all these things would motivate them to actually use the online platform and enjoy their learning process. Training could provide the experience needed to better use the technology and be updated with easier ways to do the needed task. Normally students possess basic skill level to use the technology which frustrates them when using a more advanced LMS or online system, getting them acquainted with the technology they are going to use affects their acceptance.

The analysis shows that $64.1 \%$ of the variance in perceived ease of use is explained by three factors; student online self-efficacy, instructor online self-efficacy and organizational support but the most influencing is student online self-efficacy. which means that the students will adopt the online learning if they find it easy is to access information using the online platform and easy to interact with instructor and colleagues then they will be encouraged to adopt this way of learning.

The mediating effect of the perceived usefulness enabled the students to accept the use of the online learning as they believed it will enhance their performance, their effectiveness in learning, increase their productivity, improve their grades, decrease their efforts and will make the subject more interesting.

Thus training the students on ways to improve their experience with the platform and the different tools available will improve their efficiency and eliminate wasted time and efforts, hence improve their productivity and effectiveness.

The instructor efficacy also has no impact on the intension to use online learning. Having a helpful instructor that is able to resolve technical issues and problems that might occur when using the online system didn't really affect the intension to use the online learning. In addition to the way the instructor presented the material in an interactive way or how engaged he/she was, or their ability to control the online session ,all these factors had no significance to the intension to use that is why the hypothesis testing the impact of instructor efficacy on intension to use was rejected. Although other researches proved contrary to this but according to Egyptian students they were emotionally affected by the instructor attitude. So here the mediating effect of the PEOU and PU added high significance. This means that when the instructor views the easiness of the platform, this impacts adoption because the students are affected with the attitude of the instructor. In the Egyptian context, the instructor might be familiar with the subject and possess teaching skills in physical settings but when teaching online due to lack of virtual competency frustration occurs. This could greatly affect the curriculum or the content of the subject, not knowing the right tools to use might affect their performance and productivity as well. Some of the instructors believed that using the online learning has made it harder in communication even if cameras are on. So how easy to use the virtual 
platforms affected the intension to use to a great extent. Also perceiving the usefulness, regarding saving time, efforts was extremely crucial. Valuing the benefits of the online and how it facilitated the learning process during hard times seemed to impact the students' intensions to use the online learning. Providing the instructors with new learning techniques and online tools that enhance the online learning experience is highly needed. Having flexible schedules and assessment tools would raise the benefits of the online learning. Regular training updates and internet speed is also recommended to decrease their frustration. Since the internet speed in most of the Egyptian university is very slow which results in continuous malfunction.

The organizational support in our case the university support has a positive impact on the intension to use online learning. As explained above the support done by the university affects both the students and the instructors. This support might be provided through training workshops, videos explaining the platforms, instruction manuals explaining how to better use the system. Good technical support when problems faced, like uploading errors, uploading capacity, downloading issues. The support done during exams, whether to provide assisting tools, guiding students or instructors on things to overcome or resolving problems occurring due to internet cuts.

In addition to the above finding, it was proved that the mediating effect of PEOU and PU was significant as well. The universities providing regular information on how to better use the system to both students and instructor affects the intention to use.

The findings revealed that, $65.9 \%$ of the variance in perceived usefulness is explained by three factors: student online self-efficacy, instructor online self-efficacy, and organizational support. But the most influencing is organizational support, which means that the university support providing training, design and feature of platform, technical support for both instructors and students affect the perceiving of its value to use the online learning.

To conclude all hypotheses showed that there is no significant relation between the independent external factors with the exception of (organizational support) and the dependent intension to use online learning which means that only the university support is directly vital for encouraging intension to use the online learning. The hypothesis that included the mediating variable all were accepted which means that taking the mediating effect TAM greatly affected the intension to use online learning.

Furthermore, the findings showed that there was a difference between post graduates and undergraduates data regarding the intension, perceived ease of use and perceived usefulness. Postgraduates tend to perceive the ease of use and the usefulness better and this affected their intension to use. Which might be due to the willingness to receive the education for career advancement, also the online saved them time and effort due to busy working schedule. Some postgraduate live in different geographic areas so the online learning made it easier to receive their courses from convenient places to them whether home, work or else.

The findings of this study showed no difference between private and public universities which means that public universities has improved their online systems, features, design and support to meet the highly paid private universities and that has encouraged the students to use the online learning. The demographic variables of age, gender, location didn't add much to the study and had no impact on the intension to use online learning in the Egyptian context.

\section{Conclusion}

From the above findings managing the online learning is highly needed from the university side. For the following reasons. First, boosting university students' online-learning self-efficacy would result in a highly competitive learner that is demanded by the market. This could be done by having a well-crafted strategy providing needed training and manuals. 
Second, instructor self-efficacy should be given high emphasis as the attitudes of the instructor influence the students to a great deal. Providing tools, updates, encourage the instructors to attend seminars and workshops to learn how to adopt technology.

Thirdly, the university should develop more user-friendly and user-oriented online learning platforms.

\section{Implications}

From conceptual standpoint, the current study provides a full understanding of the external factors that impacts the intension to use online learning after covid-19 since it was a sudden unprepared move to the Egyptian universities.

The key source of originality here is that little research in conducted in the Egyptian context and great demand by universities needed to better understand how to motivate students to use the online learning.

According to Hammod (2010), focus was on the student dimension, instructor dimension and technology dimension to see the impact on e-learning. Further (Saud Al-Nefaie 2015) focused on the impact of university support and instructor's attitude factor .

Therefore, the main contribution of this study is that it addresses the factors affecting the intension to use online learning and how the mediating effect explained by the TAM had an impact.

The role of demographic variables like gender, age. University type, geographic location did not have any influence on the intension. Only the education level whether posts or undergraduate had an influence on intension to use online learning.

This provides a better understanding of the factors affecting the intension to use online learning in Egypt higher education systems. Universities nowadays should focus on their technical support and modifying their online systems adding more interactive features and aids for students and instructors.

\section{Limitations \& Future Research}

In terms of limitation, the sample size needed to be larger so that we can generalize the results better; therefore future research is advised to have larger sample size representing more private and public university students and instructors. A separate instructor analysis to add to the perception of the instructor intending to use online learning as well. Also, it would be interesting to validate this model in a different culture by repeating similar studies in other similar Arabic countries, i.e. Emirates, to compare the results of the study. So, it is recommended for future research to use qualitative data collection method such as focus groups, interviews to get more insight.

In order to get a more in-depth understanding of such complex issue in the Egyptian context, it is recommended to include more variable like peer influence, subject complexity, income level.

\section{Appendix}

\section{Questionnaire Questions}

\begin{tabular}{|c|c|}
\hline \multirow{2}{*}{$\begin{array}{l}\text { Student Online } \\
\text { Self-efficacy }\end{array}$} & I have the needed skills for using an online learning system. \\
\hline & I am able to use the internet with confidence when studying online \\
\hline \multirow{4}{*}{$\begin{array}{c}\text { Instructor Online } \\
\text { Self-efficacy }\end{array}$} & The instructor was able to help me to resolve any technical problem when using the online platform. \\
\hline & The instructor presented the material in a more interactive way when learning online \\
\hline & I find the instructor more engaged with me when learning online \\
\hline & The instructor is able to control and handle the session more online \\
\hline
\end{tabular}




\begin{tabular}{|c|c|}
\hline \multirow{3}{*}{$\begin{array}{l}\text { Organizational } \\
\text { Support }\end{array}$} & Students receive training (videos,workshops...) on how to use online tools \\
\hline & the university provides good technical support for the online educational platforms \\
\hline & Instructors receive training (videos,workshops...) on how to use online tools \\
\hline \multirow[t]{2}{*}{ Perceived Usefulness } & The online learning helps me improve my grades. \\
\hline & $\begin{array}{l}\text { The online system makes the subject more interesting } \\
\text { The online system decreases my effort }\end{array}$ \\
\hline \multirow[t]{3}{*}{ Ease of Use } & I can easily access the information I am looking for when using The online platform \\
\hline & The online system enables me to interact easily with my instructor and my colleagues. \\
\hline & I find the Online platform easy to use \\
\hline \multirow[t]{2}{*}{ Intention } & I am going to use online education system in the future to improve my skills. \\
\hline & I am going to be a regular user of online learning system \\
\hline
\end{tabular}




\section{REFERENCES}

Patricia, A. (2020). "College students' use and acceptance of emergency online learning due to COVID-19", International Journal of Educational Research Open, Vol. 1, Pp. 1-8

- Al- Adwan Amer, Al- Adwan \& Ahmed, Smedley, J. (2013). "Exploring students' acceptance of e-learning using technology acceptance model in Jordanian universities", International Journal of Education and Development Using Information and Communication Technology, Vol. 9, Issue 2, pp. 4-18.

- $\quad$ Alenezi, A. (2012). "Faculty members' perception of e-learning in higher education in the Kingdom of Saudi Arabia (KSA)", Dissertation for the Degree of Doctor of Education, USA, Texas Tech University.

- Alex A. Nwankwo. (2015). “Students' learning experiences and perceptions of online course content and interactions", Doctoral Dessertation of Education, Walden University, USA, P. 50

- $\quad$ Alhumaid, K.; Ali, S.; Waheed, A.; Zahid, E. \& DHabe, M. (2020). “COVID-19 \& eLearning: Perceptions \& attitudes of teachers towards e-learning acceptance in the developing countries", Multicultural Education, Vol. 6, Issue 2, pp. 45-67.

- Allo, M. D. G. (2020). "Is the online learning good in the midst of Covid-19 Pandemic? The case of EFL learners", Journal Sinestesia, Vol. 10, No. 1, pp. 1-10.

- Almarabeh, T. (2014). "Students' perceptions of e-learning at the university of Jordan", International Journal of Emerging Technologies in Learning (IJET). 9 (3), pp. 31-35.

- $\quad$ Al-Nefaie, S. (2015). "Investigating factors influencing students' attitude and performance when using web-enhanced learning in developing countries: The case of Saudi Arabia", Doctor of Philosophy Degree, London: Brunel University, School of Information Systems, Computing and Mathematics, Department of Information Systems and Computing.

- Angela, Sylvia; C. Handoko \& Abdurachman, E. (2018). “E-learning acceptance analysis using technology acceptance model tam: Case study: Stmik mikroskil", Journal of Theoretical and Applied Information Technology, 96 (19), 6292-6305.

- $\quad$ Annan, D. L. (2008). “Education teaching methods and curriculum computers: Computers assisted instruction, Distance Learning, 5 (1), 13-17.

- $\quad$ Arkorful, V. (2014). "The role of e-learning, the advantages and disadvantages of its adoption in Higher Education", International Journal of Education and Research, Vol. 2, No. 12, December, pp. 397- 410.

- $\quad$ Richardson, J. \& J. Newby T. (2006). “The role of students' cognitive engagement in online learning", American Journal of Distance Education, 20 (1):23-37.

- Chung, E.; Subramaniam, G. and Dass, L. C. (2020). “Online learning readiness among university students in Malaysia amidst COVID-19", Asian Journal of University Education, Vol. 16 No. 2, pp. 46-58.

- Chen, X. \& Sun, A. (2016). “Online education and its effective practice: A research review”, Journal of Information Technology Education: Research, Vol. 15, pp. 157-190.

- Coman, C.; Gabriel, L.; Meses, An-Schmitz, L. \& Stanciu, C. (2020). “Online teaching and learning in higher education during the Coronavirus Pandemic: Students' perspective", Multidisciplinary Digital Publishing Institute Journal, pp. 1-24.

- Davis F. D. (1989). “Perceived usefulness, perceived ease of use, and user acceptance of information technology", MIS Quarterly, 13, pp. 319-339. 
Drane, C.; Vernon, L. \& O'Shea, S. (2020). The impact of 'learning at home' on the educational outcomes of vulnerable children in Australia during the COVID-19 pandemic. Centre for student equity in higher education, Curtin University, Australia.

- $\quad$ El-Seoud, S.; Taj-Eddin, I.; Seddiek, N.; Ghenghesh, P. \& El-Khouly, P. (2014). "The impact of e-Learning on Egyptian higher education and its effect on learner's motivation: A case study, Computer Science and Information Technology 2 (3), 179-187.

- $\quad$ Fischer, H.; Heise, L.; Heinz, M.; Moebius, K.; Koehler, T. (2014). “E-learning trends and hypes in academic teaching: Methodology and findings of a trend study", In: The International Association for Development of the Information Society (IADIS), International Conference on Cognition and Exploratory Learning in the Digital Age (CELDA), Porto, Portugal, 25-27; pp. 63-69.

- Garrison, R. (1990). "An analysis and evaluation of audio teleconferencing to facilitate education at a distance", The American Journal of Distance Education, 4 (3), 15-23.

- Gayan Nayanajith, D. A. \& Damunupola, K. A. (2021). “Impact of perceived behavioral control on e-learning adoption", Interdisciplinary Research in Education, 5 (1-2),1-14.

Habes, M. (2019). "The influence of personal motivation on using social TV: A uses and gratifications approach", International Journal of Information Technology and Language Studies, 3 (1), pp. 32-39.

- $\quad$ Hair, J. F.; Risher, J. J.; Sarstedt, M. \& Ringle, C. M. (2019). “When to use and how to report the results of PLS-SEM", European Business Review. Vol. 31, No. 1, pp. 2-24.

- Hammad, A. and Zohry, M. (2020). “Obstacles hindering the implementation of e-learning in the faculties of tourism and hotels in Egyptian public universities", Journal of Association of Arab Universities for Tourism and Hospitality (JAAUTH), Vol. 18 No. 2, pp. 76-95.

- Hammoud, L. (2010). Factors affecting students: attitude and performance when using a web-enhanced learning environment." Department of information systems and computing, Brunel University.

- $\quad$ Hung, M. L.; Chou, C.; Chen, C. H. \& Own, Z. Y. (2010). “Learner readiness for online learning: Scale development and student perceptions", Computers and Education, Vol. 55, pp. 1080-1090.

- Hussein. A.; Yousef, A. \& Sheirah M. (2009). "E-learning in the Egyptian public universities: Overview and future prospective", Human and technology development foundation at Cairo, Conference paper, is with the National e-Learning Center, Supreme Council of Universities, Egypt. https://www.researchgate.net/publication/259483851eLearning_in_the_Egyptian_Public_UniversitiesOverview_and_Future_Prospective

- $\quad$ Keller, C. S. \& Hrastinski, Carlson, S. (2007). Students' acceptance of e-learning environments: A comparative study in Sweden and Lithuania association for information systems AIS electronic library (AISEL), European Conference on Information Systems (ECIS), pp. 395-406.

- Keller, C. (2005). “Virtual learning environments: Three implementation perspectives. Learning, Media and Technology, 30 (3), 299-311.

- $\quad$ Kemp, A.; Plamer, E. \& Strelan, P. (2019). "A taxonomy of factors affecting attitudes towards educational technologies for use with technology acceptance models", British Journal of Educational Technology, Vol. 50, No. 5, pp. 1-20

- Laaser, W. (2011). "Economics of distance and online learning: Theory, practice and research", International Review of Research in Open and Distance Learning, 12 (2), pp. 138-142. 
Maajoon, A. \& Alenezi, M. A. (2012). “Faculty members' perception of e-learning in higher education in the Kingdom of Saudi Arabia (KSA)", A Dissertation in Educational Instructional Technology, Texas Tech University, USA, P. 13

- Mahyoob, M. (2020). "Challenges of e-Learning during the COVID-19 Pandemic experienced by EFL learners", Arab World English Journal, 11 (4), pp. 351-362.

- Mekky, S. (2021). “On-line learning assessment: Egyptian universities as a case study", International Journal of Information and Education Technology, Vol. 11, No. 10, pp. 471- 478

- Mittal, A.; Mantri, A.; Tandon, U. \& Dwivedi, Y. (2021). "A unified perspective on the adoption of online teaching in higher education during the COVID-19 pandemic", Information Discovery and Delivery, pp. 1-32. htttps:/www.emerald.com/insight/content/doi/10.1108/IDD-09-20200114/full/pdf

- $\quad$ Mok, K.; Xiong, W. \& Nor, H. (2021). “COVID-19 pandemic's disruption on university teaching and learning and competence cultivation: Student evaluation of online learning experiences in Hong Kong", International Journal of Chinese Education, 10 (1), pp. 1-20.

Muthuprasad, T.; Aiswarya, S.; K. S. Aditya \& Girish K. Jha. (2021). "Students' perception and preference for online education in India during COVID -19 Pandemic", Social Sciences \& Humanities, Open 3, pp. 1-11.

- https://reader.elsevier.com/reader/sd/pii/S2590291120300905?token=C1DFA0484500988573A0A841FA637E2586E303A94BB906983F3E933898F5A9104D2BC2D68CC1620F15C7EB1DEE47B2F1\&originRegion=eu-west-1\&originCreation=20220105191557

- Nafrees, A.; Roshan, A.; Baanu, N.; Nihma F. and Shibly, F. (2020). Awareness of online learning of undergraduates during COVID 19 with special reference to South Eastern University of Sri Lanka", Journal of Physics Conference Series, pp.1-10.

- Nassuora, A. B. (2013). "Students acceptance of mobile learning for higher education in Saudi Arabia", International Journal of Learning Management Systems. 1, No. 1, 1-9, pp. 1-9.

- Ngampornchai, A. \& Adams, J. (2016). “Students' acceptance and readiness for e-learning in Northeastern Thailand", International Journal of Educational Technology in Higher Education, 13:34, Pp. 2-13.

- $\quad$ Nitzl, Christian; Jose L. Roldan \& Gabriel Cepeda. (2016). "Mediation analysis in partial least squares path modeling: Helping researchers discuss more sophisticated models", Industrial Management \& Data Systems, Vol. 116, No. 9, pp. 1849-1864.

- Park, S. (2009). "An analysis of the technology acceptance model in understanding university students: Behavioral intention to use e-learning", Educational Technology \& Society, 12 (3), 150162.

- $\quad$ Prime Minister Decision \# 1200, Year 2020, Issue 24. Official Gazette -Available: https://gate.ahram.org.eg/Media/News/2020/6/17/2020-637280080642091246-209.pdf

- $\quad$ Salloum, A.; Alhamad, A.; Al-emran, M.; Abdelmonem, A. \& Shalaan, K. (2019). "Exploring students' acceptance of e-learning through the development of a comprehensive technology acceptance model, IEEE Access, Vol. 7, pp. 445-462.

- Shahin, Y. (2021). "Evaluating distance learning experience in Egyptian schools in light of the Corona crisis and its Developments", Journal of Research in Curriculum, Vol. 7, No. 1, Pp. 57-94.

- Sun, L.; Tang, Y. \& Zuo, W. (2020). “Coronavirus pushes education online”, Nature Materials, 19 (6), 687. 
- Supreme Council of Universities. Available: https://scu.eg//

- Tan, C. (2021). "The impact of COVID-19 pandemic on student learning performance from the perspectives of community of inquiry", Corporate Governance: The International Journal of Business in Society, Vol. 21, No. 6 , pp. 1215- 1228.

- Thongsri, N.; Shen, L. and Bao, Y. (2019). "Investigating academic major differences in perception of computer self-efficacy and intention toward e-learning adoption in China", Innovations in Education and Teaching International, Vol. 57, Issue5, pp. 577-589.

- Tzivinikou, A.; Charitak, G. \& Kagkara D. (2020). “Distance education attitudes (DEAS) during Covid-19 crisis: Factor structure, reliability and construct validity of the brief DEA scale in Greek-speaking SEND teachers", Technology, Knowledge and Learning, Vol. 16, pp. 1-19.

- Venkatesh, V.; Morris, M. G.; Davis, G. B. \& Davis, F. D. (2003). “User acceptance of information technology: Toward a unified view, MIS Quarterly, 2 (3), 425-478.

- Vululleh, P. (2018). “Determinants of students' e-learning acceptance in developing countries: An approach based on Structural Equation Modeling (SEM)", International Journal of Education and Development Using Information and Communication Technology (IJEDICT), Vol. 14, Issue 1, pp. 141-151.

- Wahab, A. (2008). “Modeling students' intention to adopt e-learning: A case from Egypt", The Electronic Journal of Information Systems in Developing Countries, 34, 1, 1-13.

- Yan, L.; Wainwright, A.; Guan, Q.; Wen, G. \& Gašević, D. (2021). "Students' experience of online learning during the COVID-19 pandemic: A province-wide survey study", British Educational Research Association, Vol. 52. pp. 2038-2057 https://bera-journals.onlinelibrary.wiley.com/doi/ epdf/10.1111/bjet.13102 